\title{
The Role of Ethnomathematics in Mathematics Education
}

\author{
Pedro Palhares and Lawrence Shirley
}

\section{Report}

Kay Owens (Charles Stuart University, Dubbo, NSW, Australia) presented a paper illustrating how schools can change when funds are available to assist schools and communities to implement appropriate and effective professional development, to establish partnerships between school and community, to revise teaching approaches and curriculum, to overcome disadvantage, and to value family and Aboriginal cultural heritage. She stressed that the people involved and their planning are critical for transformation. The schools were in a Smarter Stronger Learning Community so they supported each other across schools but other programs in the various schools were also important in achieving change.

Zhou Chang-jun, Shen Yu-hong, Yang Qi-xiang (Dehong Teachers' College) presented a paper about Dai ethnic mathematical culture, which is an important part of Dai ethnic culture. Mathematical elements show in their daily life. Through a research project of the Yunnan Dehong Dai people in southwest China, they collected the first-hand information, tried to do a small investigative study, and collected mathematics teaching resources that are useful to primary and secondary schools students on mathematics learning in this minority areas.

Organizers Co-chairs: Pedro Palhares, Lawrence Shirley; Team Members: Willy Alangui (Philippines), Kay Owens (Australia), Paulus Gerdes (Mozambique), Ho Kyung Ko (Korea); Liaison IPC Member: Bill Barton (New Zealand).

P. Palhares $(\square)$

University of Minho, Braga, Portugal

e-mail: palhares@ie.uminho.pt

L. Shirley

Towson University, Towson, USA

e-mail: LShirley@towson.edu

(C) The Author(s) 2015

S.J. Cho (ed.), The Proceedings of the 12th International Congress

on Mathematical Education, DOI 10.1007/978-3-319-12688-3_61 
Annie Savard (McGill University) discussed problems of bridging the Inuit culture of northern Canada with the official and cultural requirements of Canada's school mathematics curriculum, especially when goals seem to clash.

Igor Verner, Khayriah Massarwe and Daoud Bshouty (Technion - Israel Institute of Technology) presented a paper discussing pathways of creativity and focusing on the one going through practice in creation and analysis of useful and mathematically meaningful artifacts. They propose to involve prospective teachers in practice of construction and analysis of geometric ornaments from different cultures as well as in teaching geometry. They considered perceptions and attitudes that triggered students' creative learning behavior in this context.

Milton Rosa and Daniel Clark Orey [Universidade Federal de Ouro Preto (UFOP)] think that the application of ethnomathematical techniques and tools of modeling allows us to examine systems taken from reality and offers us an insight into forms of mathematics done in a holistic way. According to them, the pedagogical approach that connects a diversity of cultural forms of mathematics is best represented through ethnomodeling, a process of translation and elaboration of problems and the questions taken from academic systems. Seen in this context, they attempted to broaden the discussion of possibilities for the inclusion of ethnomathematics and associated ethnomodeling perspectives that respect the social diversity of distinct cultural groups with guarantees for the development of understanding different ways of doing mathematics through dialogue and respect.

Karen Francois [University Brussels (Vrije Universiteit Brussel)] and Rik Pinxten (University Ghent) started by the statement from the Vygotsky and the Cultural psychology approach (M. Cole) that 'learning is situated, socioculturally contextualized'. Learning happens in the space of background/foreground (of the learner) in his or her particular environment of experience. Math learning implies an implicit understanding, categorizing and conceptualization of reality. e.g., set theory implies intrinsically a part-whole framing of reality. They think that the tremendous dropout from math classes and the structural gap between good and bad performers (PISA) is caused by disregarding the linguistic and socioculturally formatted background/foreground of the learners. They want to use anthropological study in the classroom to know/map the child's background/foreground and adapt the entry into mathematics courses accordingly, hence their option for multimathemacy.

Maria do Carmo S. Domite (Faculty of Education, University of São Paulo) (electronically) presented an attempt to make possible an approach between ethnomathematics and the mathematics learning processes in the scholar contexthowever it does this from an ethnomathematician's point of view, not that of a Cognitive Psychology studious. She therefore focused on two notions of the mathematics education processes: the notion understood as the student's "prerequisite" and the notion of the teacher's "listening". She brought to the centre of discussion that the teacher should know to understand the students' initial mathematics knowledge- how he/she uses them-, as well as know how to listen to what the students have to say-respecting the cultural and social differences in order to help them build a more critical and elaborate thinking about mathematics ideas. 
Andrea V. Rohrer (Universidade Estadual Paulista) and Gert Schubring (Universidade Federal do Rio de Janeiro) started to remember that since the creation of the International Study Group on Ethnomathematics, several researchers have debated on how could or should a theory of ethnomathematics exist, and, if so, how it is to be conceptualized. So far, there exists no consensus on how this theory should be defined. During the last International Conference on Ethnomathematics (ICEM-4) in Towson, Maryland (July, 2010), Rik Pinxten emphasized on the necessity of reopening this debate. Ethnomathematics will only be acknowledged by other scientific communities if we, as ethnomathematicians, are able to establish a proper conceptualization of this field of study. They presented one possible approach to a conceptualization of a theory of ethnomathematics a theory that needs to be regarded as an interdisciplinary discipline that covers theories from both the exact and social sciences.

Alexandre Pais (Aalborg University) and Mônica Mesquita (University of Lisbon) consider that the push to marry off local and school knowledge has been a growing concern within educational sciences, particularly in mathematics education where a field of studies by the name of ethnomathematics has been producing research around the uses people do of mathematics outside school's walls. Notwithstanding the good will of educational agents in bringing to schools local knowledges, criticisms have been made on the sometimes naive way in which such a bridge is theorized and implemented. After a brief description of these criticisms, they presented the Urban Boundaries Project as an attempt to avoid the inconsistencies of schooling, and the promotion of a non-scholarized ethnomathematics.

Joana Latas (EBI/JI de Aljezur, CIEP-U. Évora) and Darlinda Moreira (Universidade Aberta) claim that the integration of cultural aspects in curricula is a means of legitimizing students' experiences and of answering to the cultural diversity in favor of a meaningful mathematical learning. (e.g. Bishop 2005; Gerdes 2007; Moreira 2008). They attempted to highlight the role of cultural mathematics in the development of the predisposition to establish mathematical connections. Such an objective was framed in a broader investigation (Latas 2011) in which a curricular project was developed, whose conceptualization followed an ethnomathematical approach. The results suggest that students: (i) appropriated cultural distinct practices through the relation that they established with their previous knowledge; (ii) gradually revealed a greater predisposition to establishing mathematical connections; (iii) deepened local and global mathematical knowledge in the interaction between both dimensions.

Roger Miarka (Universidade do Estado de Santa Catarina, Brazil) and Maria Aparecida Viggiani Bicudo (Universidade Estadual Paulista, Brazil) presented a paper, based on a $\mathrm{PhD}$ research, aiming to discuss the conception of mathematics, and its developments in terms of methodology, of five preeminent ethnomathematics researchers: Bill Barton (University of Auckland, New Zealand), Eduardo Sebastiani Ferreira (Universidade Estadual de Campinas, Brazil), Gelsa Knijnik (Universidade do Vale do Rio Sinos, Brazil), Paulus Gerdes (Centro Moçambicano de Investigação Etnomatemática, Mozambique) and Ubiratan D'Ambrosio (Universidade Bandeirante de São Paulo, Brazil). The research was carried out 
under a phenomenological perspective, and its methodology involved an interview with each of the above-mentioned researchers. Theses interviews were analyzed hermeneutically, and through phenomenological reductions, thematic categories were articulated. In this presentation they brought the category about the presence of mathematics within ethnomathematics.

Also, there were several posters and short presentations, including reports from Portugal (Pedro Palhares), Tibet (Xiawu Cai Rang), Nepal (Bal Luitel and Amril Poudel), Philippines (Rhett Latorio), China (Xueying Ji), Mozambique (Marcos Cherinda) and Zambia (Mitsuhiro Kimura), especially on details of local mathematics and applications of local culture in school mathematics.

Marcos Cherinda made a special presentation, inviting participants (and all interested in ethnomathematics) to attend the Fifth International Conference on Ethnomathematics (ICEM-5), to be held in July 2014 (specific date to be announced), in Chidenguele, Gaza, Mozambique.

\section{Participants}

There were thirty-five participants (from twenty-two countries) in the TGS-36 sessions: Maria Aparecida Bicudo (Brazil), Bill Barton (New Zealand), Marcos Cherinda (Mozambique), Sandy Dawson (USA), Tournés Dominique (France), Cris EdmondsWathen (Australia), Karen François (Belgium), Kgomotso Garegae (Botswana), Kangu Hyun Jin (Korea), Jason Johnson (United Arab Emirates), Traore Kalifa (Burkina Faso), Jiyeon Kim (Korea), So Yoang Kim (Korea), Mitashiro Kimura (Japan), Ho Kyung Ko (Korea), Rhett Latonio (Philippines), Joana Latas (Portugal), Chan Gyu Lee (Korea), Bal Luitel (Nepal), Danilo Mamangon (Micronesia), Roger Miarka (Brazil), Epi Moses (Palau), Kay Owens (Australia), Alexandre Pais (Denmark), Pedro Palhares (Portugal), Amrit Poudel (Nepal), Andrea Rohrer (Brazil), Annie Savard (Canada), Lawrence Shirley (USA), Edmir Terra (Brazil), Koichi Tomita (Japan/Malaysia), Rhoda Velasques (Philippines), Igor Verner (Israel), Lim Byong Yang (Korea), Hossein Zand (United Kingdom).

Open Access This chapter is distributed under the terms of the Creative Commons Attribution Noncommercial License, which permits any noncommercial use, distribution, and reproduction in any medium, provided the original author(s) and source are credited. 